\title{
Sensation Seeking and Adolescent Cigarette Smoking: Examining Multiple Pathways in Cross-Sectional Data
}

\author{
Smita C. Banerjee ${ }^{*}, 1$ and Kathryn Greene ${ }^{2}$ \\ ${ }^{1}$ Communication and Health Issues Partnership for Education and Research at Rutgers University, USA \\ ${ }^{2}$ Department of Communication, Rutgers University, 4 Huntington Street, New Brunswick, NJ 08901, USA
}

\begin{abstract}
This study applies Jessor and Jessor's problem behavior theory to examine factors predicting adolescent smoking behavior both directly and indirectly. Measures include adolescent smoking and other psychosocial variables including sensation seeking, peer smoking behavior, parental monitoring, and delinquent behaviors. Middle school students $(N=$ 260) from two schools in the northeast United States participated in the study. The results indicate that sensation seeking and parental monitoring contribute to adolescent smoking indirectly, through the mediation of peer smoking behavior and engagement in delinquent behaviors. Peer smoking behavior and delinquent behaviors predict adolescent smoking directly. Implications of these findings are discussed.
\end{abstract}

Keywords: Adolescent smoking, peer smoking, parental monitoring, problem behavior theory, sensation seeking.

Tobacco use primarily begins in early adolescence [1]. Each day, 6000 children under 18 years smoke their first cigarette [2]. Mowery, Farrelly, Haviland, et al. [3] report that $51 \%$ of the US population aged 11 to 18 years have tried smoking and about 300,000 adolescent established smokers are in the age group of 11 to 14 years. Each year smoking causes approximately 435,000 premature deaths and over 5 million years of potential life lost [4]. Findings from the Global Youth Tobacco Survey (GYTS) suggest that tobacco use will contribute to more than 10 million deaths per year by 2020 [5]. The Centers for Disease Control and Prevention [6] estimate that 6.4 million current child smokers will eventually die prematurely from a smoking-related disease.

The Surgeon General's report of 1994 described the health problems caused by cigarette smoking among young people, including cough and phlegm production, an increase in the number and severity of respiratory illnesses, decreased physical fitness, and potential retardation in the rate of lung growth and the level of maximum lung function [7]. When smoking begins at an early age, the risk of heavy smoking and nicotine addiction increases [8]. Tobacco use in adolescence is also associated with a range of health-compromising behaviors including being involved in fights, carrying weapons, engaging in high-risk sexual behavior, and using alcohol and other drugs [9].

Given such alarming incidence and consequences of cigarette smoking, it is key to explore reasons why adolescents begin smoking. The present study examines the role of different personality, environmental, and behavioral predictors of adolescent smoking by employing problem behavior theory $[10,11]$. Problem behavior theory has been utilized in past research to examine adolescent and/or youth smoking $[12,13]$. For instance, Costa et al. [13] employed factors such

\footnotetext{
*Address correspondence to this author at the Communication and Health Issues Partnership for Education and Research, Rutgers University, 4 Huntington Street, New Brunswick, NJ 08901, USA;

E-mail: smita.banerjee@gmail.com
}

such as perceived peer pressure, stress, depression, selfesteem, academic involvement, and religious involvement to predict college student cigarette smoking. The present study uses a different subset of risk and protective factors such as sensation seeking, peer smoking, and parental monitoring in predicting adolescent rather than college smoking. These factors have been studied independently to predict adolescent smoking $[14,15]$ but have not been studied under a comprehensive framework of problem behavior theory. The present study also examines if these factors contribute to adolescent cigarette smoking directly or through the mediation of delinquent behavior, a variable under the behavior system.

\section{PROBLEM BEHAVIOR THEORY}

Problem behavior theory posits that three systems of psychosocial factors influence problem behaviors: the personality system (e.g., self-esteem, sensation seeking), the perceived environment system (e.g., peer pressure, parental involvement), and the behavior system (e.g., school performance, other delinquent behaviors). Examined simultaneously, these systems explain the likelihood of occurrence of risktaking behaviors such as smoking, alcohol consumption, and unsafe sex [16]. Variables within each system represent either risk or protective factors. Risk factors, such as attitudinal tolerance of deviance, enhance the likelihood of engaging in a particular problem behavior. Protective factors, such as academic achievement, on the other hand, reduce that likelihood. The relative weighting of risk and protective factors predict the overall likelihood of occurrence of problem behavior $[10,17]$. However, it is not clear if the variables in each of the systems predict the overall likelihood of problem behavior directly or indirectly, through the mediation of other variables. The present study attempted to unravel these relationships.

\section{Adolescent Cigarette Smoking: A Problem Behavior}

In order to understand the conceptualization of adolescent cigarette smoking, Turbin, Jessor, and Costa [18] examined if adolescent cigarette smoking fits into a structure of 
problem behaviors (such as alcohol abuse, delinquency, and illicit drug use) or health compromising behaviors (such as unhealthy dietary habits and insufficient exercise). Problem behaviors were defined as behaviors that transgress social and legal norms and often elicit sanctions from others or the larger society [17]. Health compromising behaviors were defined as ones that endanger health but do not necessarily violate social or legal norms or result in sanctions [18]. The results suggested that adolescent cigarette smoking fits the problem behavior structure more than the healthcompromising behavior structure because adolescent smoking may be "motivated by goals such as rejecting the norms of conventional society, affirming membership in a peer group, asserting independence from parents, or being seen as more mature" (p. 116) [18]. Thus, the present study conceptualizes adolescent cigarette smoking as a problem behavior and examines the contribution of psychosocial and behavioral protective and risk factors in influencing adolescent cigarette smoking.

\section{Interrelationships Between Different Systems}

The progression and sequence of experiences leading to substance abuse has been addressed in recent research on adolescents. Kandel and Jessor [19] suggest that substance use progression may commence from a more complex development sequence of activities including other key behaviors and experiences such as joining a gang, dropping out of school, etc. Yanovitzky [20] demonstrated that sensation seeking, some protective factors (such as religiosity, positive family relationship, school performance) and risk factors (such as unsupervised time with peers, frequency of school absences) contributed to association with deviant peers, which led to pro-drug discussions, and finally, to a greater intention to use drugs. Multiple pathways (both direct and indirect) explain the association between personality factors and risk behaviors. Thus, we propose to examine if the variables in the personality and perceived environment systems examine adolescent smoking directly or through the mediation of delinquent behavior, a variable under the behavior system.

\section{Sensation Seeking, Delinquent Behaviors, and Adolescent Cigarette Smoking}

Sensation seeking is a personality trait that regulates the tendency to seek varied, novel, and intense sensations and experiences [21]. Various factors explain how and why sensation seekers engage in risk behaviors. Sensation seeking motivates individuals to engage in behaviors that are high in risk and thereby exciting for them, such as drug use [21]. High sensation seekers also tend to underestimate the risk associated with health behaviors such as cigarette smoking, drug use, and alcohol consumption, and thereby engage in it more as compared to their low sensation seeking counterparts [22]. High sensation seekers also tend to have friends who engage in similar risk behaviors [20].

Direct pathway. Prior research has demonstrated that sensation seeking tendencies influence smoking initiation, experimentation, and behavior [23-25]. Higher sensation seeking adolescents gravitate towards smoking because cigarette smoking in adolescence involves taking risks or is a sign of independence, which provides stimulation for the high sensation seeking adolescent [21]. Also, cigarette smok- ing provides direct neurological stimulation for the adolescent [26]. Therefore, sensation seeking is likely to influence adolescent cigarette smoking.

Indirect pathways. Several studies have examined the relationship between sensation seeking traits and motivation to engage in risk behaviors such as alcohol consumption, drug use, and delinquency [15, 23, 27]. Engagement in delinquent behaviors such as skipping school, shoplifting, and pushing others on purpose may act as predecessors for adolescent cigarette smoking. Research has shown that delinquency and antisocial behaviors in adolescents, such as violence and vandalism, have been shown to predict later substance use including cigarette smoking [28, 29]. Hawkins, Catalano, and Miller [30] conclude that delinquent teens are often characterized by rebelliousness and as having less of a stake in conforming to conventional norms, both of which are associated with increased substance use. Therefore, there is a greater likelihood that high sensation seeking is associated with delinquent behaviors, which further contribute to adolescent cigarette smoking.

Furthermore, sensation seeking has also been associated with socialization with peers who engage in similar behaviors [20]. Using a social network analysis, Ennett et al. [31] concluded that adolescents closer in proximity to peers who are substance users themselves had a higher propensity of using substances including cigarettes. Association with friends who engage in substance use behaviors may provide easy access, favorable attitudes, and a persuasive environment that encourage an adolescent to smoke. Therefore, it is likely to assume that peer smoking behavior will mediate the relationship between sensation seeking and adolescent smoking.

\section{Peer Smoking, Delinquent Behaviors, and Adolescent Cigarette Smoking}

Peer smoking refers to the frequency of friends who smoke in an adolescent's peer group. Peer smoking has been conceptualized as the perceived prevalence of peer smoking or actual prevalence of peer smoking [32].

Direct pathway. Peer smoking behavior may influence adolescent smoking through multiple routes, such as providing social reinforcement for smoking and/or a model for the behavior [33]. Smoking peers may also provide easy access to cigarettes thereby encouraging adolescent smoking [34]. Peer smoking has been documented as a strong predictor of adolescent smoking $[35,36]$.

Indirect pathway. Peer smoking and association with friends who smoke may lead an adolescent to accept behaviors that may be unacceptable in the given social context [37]. Peer substance use may contribute to a more general pattern of delinquent behaviors [38], and the combined effects of peer smoking (in particular) and delinquency contribute to adolescent smoking [37]. Therefore, peer smoking may result in adolescent smoking behavior, albeit indirectly through first driving the adolescent towards greater engagement in delinquent behaviors, and then smoking.

\section{Parental Monitoring, Delinquent Behaviors, and Adoles- cent Cigarette Smoking}

Parental monitoring refers to the involvement and knowledge that parents have about their adolescent's plans and 
activities [14]. Parental monitoring indicates healthy family functioning [39].

Direct pathway. Prior research has shown that poor parental monitoring is associated with higher involvement in smoking, drinking, and other deviant and risky behaviors [40-42].

Indirect pathways. Poor parental monitoring has been associated with adolescent problem behaviors including delinquent behaviors [43-45]. Close parental monitoring is effective in managing adolescent behaviors because it establishes a sense of trusting relationship [45]. These findings suggest that engagement in delinquent behaviors may precede cigarette smoking [19]. Therefore, it is suggested that the relationship between parental monitoring and adolescent cigarette smoking will be mediated by engagement in delinquent behaviors.

Additionally, parental monitoring may contribute indirectly to adolescent cigarette smoking by influencing the type of peers an individual associates with $[46,47]$. Research has confirmed that parental monitoring may act as a protective factor against association with peers who engage in substance use behaviors [20]. Furthermore, adolescents who did not value spending time with parents were more apt than others to choose friends who smoked cigarettes [48].

\section{Hypotheses}

Based on the literature reviewed so far, the following hypotheses are advanced:

H1: Adolescents higher in sensation seeking will be more likely to smoke cigarettes.

H2: Engagement in delinquent behaviors will mediate the relationship between sensation seeking and adolescent cigarette smoking.

H3: Reported peer smoking behavior will mediate the relationship between sensation seeking and adolescent cigarette smoking.

H4: Adolescents with more friends who smoke will be more likely to smoke cigarettes.

Personality System Perceived Environment System Behavior System

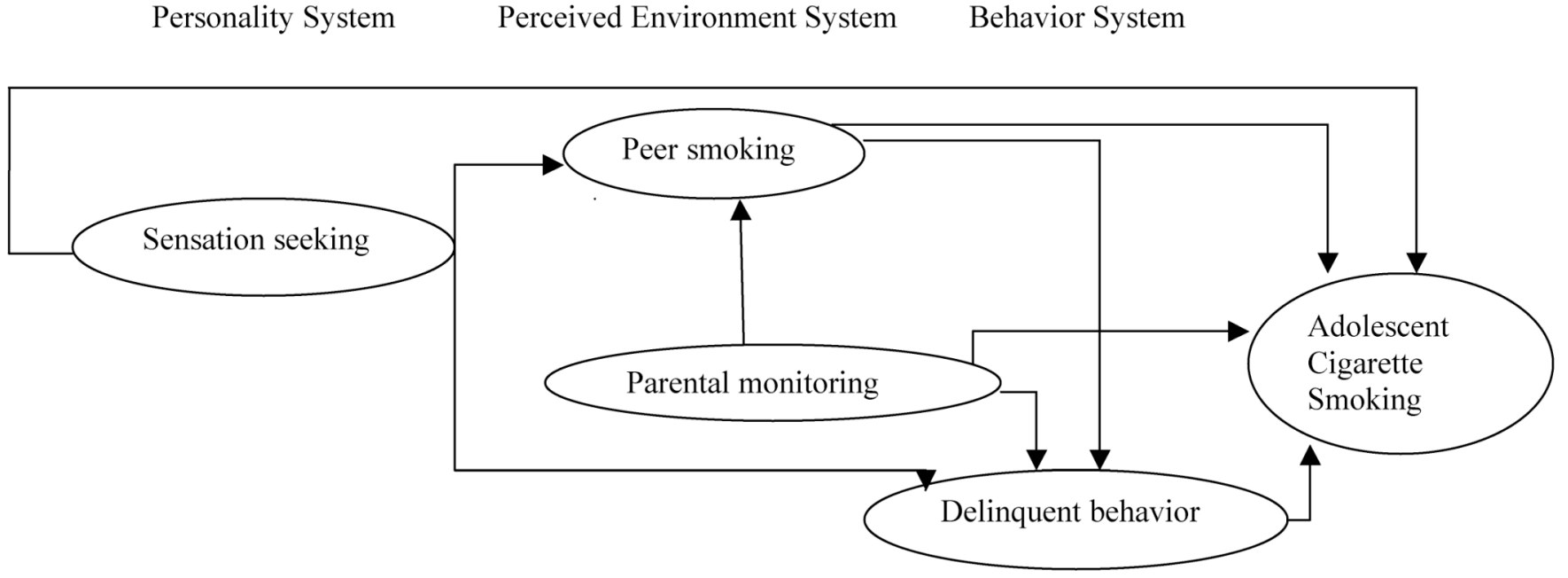

Fig. (1). Hypothesized model for direct and indirect associations between problem behavior theory variables and adolescent cigarette smoking.
H5: Engagement in delinquent behaviors will mediate the relationship between peer smoking and adolescent cigarette smoking.

H6: Adolescents with greater parental monitoring will be less likely to smoke cigarettes.

H7: Engagement in delinquent behaviors will mediate the relationship between parental monitoring and adolescent cigarette smoking.

H8: Peer smoking behavior will mediate the relationship between parental monitoring and adolescent cigarette smoking.

\section{Possible Associations Among Variables}

This paper examines the eight hypotheses advanced. As a starting point, the paper tests the linear associations between personality system variables (sensation seeking), perceived environmental system (peer smoking behavior, and parental monitoring), and behavior system (delinquent behavior) and adolescent cigarette smoking. However, personality and perceived environmental system variables may also be indirectly associated with adolescent cigarette smoking. For instance, higher sensation seeking and peer smoking behavior and lower parental monitoring motivate engagement in delinquent behaviors. These associations, in turn, may be positively related to adolescent cigarette smoking. Therefore, this study tested the proposition that personality and perceived environmental system variables contribute to adolescent cigarette smoking in both direct and indirect ways. Fig. (1) presents the proposed model.

\section{METHOD}

\section{Participants and Procedure}

After receiving human subjects approval from University Institutional Review Board, parental consent from students' parents, and verbal consent from the students, two hundred and sixty male $(n=104)$ and female $(n=156)$ students enrolled in $6^{\text {th }}-8^{\text {th }}$ grades in two northeastern schools (henceforth referred to as School A and School B) in the Unites States were recruited for the study $(N=260)$. Missing data ( $\mathrm{n}$ $=15$ ) comprised of participants who had not responded to 
half or greater number of items on the surveys, and were deleted from analyses. The final data comprised of two hundred and forty five male $(n=99)$ and female $(n=146)$ students, ranging in age from 11 to $16(M=12.50, S D=1.07)$. The sample was 74\% Hispanic, 13\% African-American, 7\% Bi/Multi-Racial, 3\% Asian, and 2\% Caucasian, and others. About $22 \%$ of the sample reported ever smoking a cigarette, and this percentage of smoking in an adolescent sample is consistent with prior studies on adolescent smoking behavior [49]. The students completed the surveys in their classrooms as part of a smoking intervention project (with teacher and researcher present) ${ }^{1}$ The questionnaire took less than 40 minutes to complete and was anonymous.

\section{Measurement Instruments}

The questionnaire measured variables included in the personality (sensation seeking), perceived environment (peer smoking behavior, parental monitoring), and behavior systems (delinquent behaviors), along with adolescent smoking behavior.

Both single-item and multiple-item measures were utilized for this study. The single-item measure consisted of peer smoking behavior. The multiple-item measures consisted of sensation seeking, parental monitoring, delinquent behaviors, and adolescent smoking behavior. After confirming the unidimensionality of each of the multiple-item scales (except parental monitoring - 2 items, and adolescent smoking behavior - different response formats), we created respective composite scores by summing and averaging responses to individual items. The resulting measures are described in the following sections.

Sensation seeking. The 8-item sensation seeking scale was created by Hoyle et al. [22] based on Form V of Zuckerman's [21] sensation seeking scale. It is a Likert-type scale with 5-point responses ranging from 1 (Strongly Disagree) to 5 (Strongly Agree). Reliability for this scale was moderate $($ alpha $=.70)$, and the scores on the scale were summed and averaged, with higher scores indicating more sensationseeking traits $(M=3.60, S D=.76)$.

Peer smoking behavior. Peer smoking behavior was measured by one item created by the authors and it asked, "Please tell us the number of your friends who you think have smoked cigarettes, even once or twice in the last 6 months." The participants were instructed to write the number of friends in a blank space. The responses ranged from 0 to $16(M=1.99, S D=2.88)$.

Parental monitoring. Parental monitoring scale was derived from the National Survey of Parents and Youth (NSPY) [50]. The scale consisted of two five-point Likert type items ranging from 1 (never true) to 5 (always true). Respondents answered the question, "In general, how often does at least one of your parents/caregivers: (1) Know what you are doing when you are away from home? (2) Have a pretty good idea of your plans for the coming day?" The two items were summed and averaged to form a composite scale

\footnotetext{
${ }^{1}$ The students completed the surveys in their classrooms as part of a smoking intervention project. The smoking intervention included multiple sessions to examine effectiveness of media literacy intervention on adolescent smoking. The data present here is comprised of participant responses to a cross-sectional survey, taken at baseline.
}

with a higher score indicating more perceived parental monitoring $(M=3.55, S D=1.14)$.

Delinquent behaviors. Delinquent behaviors scale was derived from Greene et al. [15]. The scale consisted of 12 five-point Likert type items ranging from 1 (never) to 5 (very often), such as "How often have you": been in a physical fight, skipped school, shoplifted from a store, etc. Reliability (Cronbach's alpha) was .75, and the items were summed and averaged to form a composite scale with a higher score indicating more delinquent behavior $(M=1.61, S D=.50)$.

Adolescent smoking behavior. Smoking behavior was assessed by four items derived from The National Household Survey on Drug Abuse, 2000 [51]. The four items were: (1) "Have you ever smoked part or all of a cigarette?" with answer options ranging from $0(N o)$ to 1 (Yes) $(M=.22, S D=$ $.41)$; (2) "How often have you smoked all or part of a cigarette?" with five answer options: 0 (I have never smoked a cigarette), 1 (Once or twice, but not in the last 30 days), 2 (More than twice in the past, but not in the last 30 days), 3 (Regularly in the past, but not in the last 30 days) and 4 (I have smoked in the last 30 days); (3) "How long has it been since you last smoked part or all of a cigarette?" with four answer options: 0 (Never smoked), 1 (More than 6 months ago), 2 (More than 30 days ago but within the last 6 months), and 3 (During the last 30 days); and (4) "What is your best guess of the number of days you smoked part or all of a cigarette during the last 30 days?" Participants were instructed to write their response on a blank line $(M=.73$, $S D=3.52$, Range $=0-30)$. The scores on these items were first converted to z-scores and then summed and averaged to create a variable for adolescent smoking behavior (Cronbach's alpha $=.60)$. A higher score indicated more adolescent smoking behavior (both more number of cigarettes and more frequent smoking) $(M=0.00, S D=1.00$, Range $=$ 0.41 to 3.57$)$.

\section{RESULTS}

\section{Analyses}

In order to test these cross-sectional data, we employed bivariate correlations and structural equation modeling (SEM). The SEM models tested comparative utility of personality, and perceived environment variables for understanding adolescent smoking behavior, along with the mediating (and direct) role of a behavior system variable.

\section{Preliminary Analyses}

Before testing our hypotheses, we conducted preliminary analyses. We evaluated sex, age, race, school, and grade differences on all of the variables in the study by conducting appropriate t-tests (for sex, race, and school) or oneway ANOVAs (for age, and grade). This technique has been utilized in prior research to identify any demographic differences in the variables of interest [52]. Table 1 presents the results of the t-tests (for examining sex, race, and school differences in study variables) and Table 2 presents the results of the ANOVAs (for examining grade and age differences in study variables). Results of t-tests document four significant findings: (1) male adolescents reported greater smoking behavior than female adolescents; (2) Hispanic students reported engagement in more delinquent behaviors than non-Hispanic students; (3) School B students were 
Table 1. Sex, Race, and School Differences in Study Variables

\begin{tabular}{|c|c|c|c|c|c|c|c|c|c|}
\hline \multirow{2}{*}{ Variables } & \multicolumn{3}{|c|}{ Sex Differences } & \multicolumn{3}{|c|}{ Race Differences } & \multicolumn{3}{|c|}{ School Differences } \\
\hline & $\begin{array}{c}\text { Males } \\
\text { M (SD) }\end{array}$ & $\begin{array}{l}\text { Females } \\
\text { M (SD) }\end{array}$ & t (243) & $\begin{array}{l}\text { Hispanic } \\
\text { M (SD) }\end{array}$ & $\begin{array}{c}\text { Other } \\
\text { M (SD) }\end{array}$ & t (240) & $\begin{array}{c}\text { School A } \\
\text { M (SD) }\end{array}$ & $\begin{array}{l}\text { School B } \\
\text { M (SD) }\end{array}$ & $t(243)$ \\
\hline Sensation seeking & $3.71(0.73)$ & $3.53(0.77)$ & 1.86 & $3.55(0.79)$ & $3.61(0.74)$ & -0.55 & $3.39(0.82)$ & $3.70(0.71)$ & $-3.10^{* *}$ \\
\hline Peer smoking & $2.14(2.98)$ & $1.89(2.82)$ & 0.67 & $2.47(3.14)$ & $1.85(2.80)$ & 1.44 & $2.56(3.26)$ & $1.72(2.65)$ & $2.17^{*}$ \\
\hline Parental monitoring & $3.66(1.11)$ & $3.48(1.16)$ & 1.22 & $3.59(1.18)$ & $3.55(1.12)$ & 0.27 & $3.52(1.15)$ & $3.56(1.14)$ & -0.29 \\
\hline Delinquent behaviors & $1.62(0.46)$ & $1.60(0.52)$ & 0.41 & $1.72(0.62)$ & $1.57(0.44)$ & $2.01^{*}$ & $1.57(0.61)$ & $1.63(0.43)$ & -0.87 \\
\hline Adolescent smoking & $0.14(1.03)$ & $-0.10(0.87)$ & $1.95^{*}$ & $0.03(1.01)$ & $-0.02(0.91)$ & 0.36 & $0.15(1.10)$ & $-0.08(0.85)$ & 1.76 \\
\hline
\end{tabular}

$* p \leq .05, * * p \leq .01$.

Table 2. Grade and Age Differences in Study Variables

\begin{tabular}{|c|c|c|c|c|c|c|c|c|c|c|}
\hline \multirow[b]{2}{*}{ Variables } & \multicolumn{4}{|c|}{ Grade Differences } & \multicolumn{6}{|c|}{ Age Differences } \\
\hline & $\begin{array}{c}\mathbf{6}^{\text {th }} \\
\mathbf{M}^{(\mathrm{SD})}\end{array}$ & $\begin{array}{c}7^{\text {th }} \\
M(S D)\end{array}$ & $\begin{array}{c}\mathbf{8}^{\text {th }} \\
M(\text { (SD) }\end{array}$ & $\begin{array}{c}F \\
(2,242)\end{array}$ & $\begin{array}{l}\text { 11-Year } \\
\text { M (SD) }\end{array}$ & $\begin{array}{l}\text { 12-Year } \\
\text { M (SD) }\end{array}$ & $\begin{array}{l}\text { 13-Year } \\
\text { M (SD) }\end{array}$ & $\begin{array}{l}\text { 14-Year } \\
\text { M (SD) }\end{array}$ & $\begin{array}{l}\text { 15-Year } \\
\text { M (SD) }\end{array}$ & $\begin{array}{c}F \\
(4,240)\end{array}$ \\
\hline Sensation seeking & $3.63(0.80)$ & $3.41(0.71)$ & $3.78(0.72)$ & $5.08 * *$ & $3.75(0.76)$ & $3.35(0.76)$ & $3.78(0.66)$ & $3.52(0.82)$ & $4.04(0.48)$ & $4.33 * *$ \\
\hline Peer smoking & $1.29(2.42)$ & $1.51(1.95)$ & $3.29(3.69)$ & $12.52 * * *$ & $1.02(1.57)$ & $1.26(1.73)$ & $2.73(3.92)$ & $3.17(3.12)$ & $2.07(0.93)$ & $6.10 * * *$ \\
\hline Parental monitoring & $3.78(1.09)$ & $3.51(1.23)$ & $3.34(1.06)$ & $3.07 *$ & $3.66(1.05)$ & $3.76(1.23)$ & $3.48(1.15)$ & $3.25(1.04)$ & $2.70(0.45)$ & 2.29 \\
\hline Delinquent behaviors & $1.51(0.43)$ & $1.56(0.50)$ & $1.77(0.52)$ & $6.56 * *$ & $1.55(0.44)$ & $1.49(0.41)$ & $1.62(0.48)$ & $1.87(0.64)$ & $1.70(0.42)$ & $4.43 * *$ \\
\hline Adolescent smoking & $-0.17(0.79)$ & $-0.13(0.80)$ & $0.33(1.16)$ & $7.06^{* * *}$ & $-0.13(0.88)$ & $-0.15(0.76)$ & $0.05(0.99)$ & $0.27(1.13)$ & $0.49(1.41)$ & 2.02 \\
\hline
\end{tabular}

higher in sensation seeking as compared to School A students; and (4) School A students reported more friends who smoked as compared to School B students. Results of ANOVAs indicate significant findings consistent across grade and age: (1) $8^{\text {th }}$ grade students are higher sensation seekers, report more friends who smoke, less parental monitoring, more delinquent behaviors, and more cigarette smoking as compared to $6^{\text {th }}$ and $7^{\text {th }}$ grade students, (2) 13 year old adolescents were higher sensation seekers than 12 year olds, both 13 and 14 year olds had more friends who smoked as compared to 11 and 12 year olds, and 14 year olds reported more delinquent behaviors as compared to 11 and 12-year olds.

\section{Main Analyses}

We conducted two sets to analyses to evaluate hypotheses. First, we computed zero-order correlations for all the variables in the study (Table 3). Results of bivariate correlations demonstrated that adolescent cigarette smoking is significantly associated with all the predictor variables (i.e., sensation seeking, peer smoking behavior, parental monitoring, and delinquent behavior). Results also revealed that personality and perceived environment systems variables (i.e., sensation seeking, peer smoking behavior, and parental monitoring) are significantly related to delinquent behaviors.

Next, we employed maximum likelihood SEM to further evaluate our hypotheses. The first step required calculation of the error variance $(1-\alpha)\left(\sigma^{2}\right)$ of each multiple-item variable to account for unreliability within our measures [53]. Because our preliminary analyses identified several sex, age, race, school, and grade differences in our measures, we first partialled the variance due to respondent's sex, age, race,

Table 3. Zero-Order Correlation Matrix for All Variables $(N=245)$

\begin{tabular}{|c|c|c|c|c|c|c|c|}
\hline & 1 & 2 & 3 & 4 & 5 & 6 & 7 \\
\hline 1. Adolescent smoking & 1.00 & & & & & & \\
\hline 2. Sensation seeking & $.29 * *$ & 1.00 & & & & & \\
\hline 3. Peer smoking & $.49^{* *}$ & $.25^{* *}$ & 1.00 & & & & \\
\hline 4. Parental monitoring & $-.30 * *$ & -.10 & $-.24 * *$ & 1.00 & & & \\
\hline 5. Delinquent behaviors & $.58 * *$ & $.35^{* *}$ & $.51^{* *}$ & $-.37 * *$ & 1.00 & & \\
\hline 6. Age & $.17^{*}$ & .03 & $.28 * *$ & $-.16^{*}$ & $.21 * *$ & 1.00 & \\
\hline 7. $\operatorname{Sex}^{\mathrm{a}}$ & -.12 & -.12 & -.04 & -.08 & -.03 & -.10 & 1.00 \\
\hline
\end{tabular}

${ }^{*} p \leq .01, * * p \leq .001$.

${ }^{\mathrm{a}} \operatorname{Sex}(1=$ male, $0=$ female $)$. 
Personality System Perceived Environment System Behavior System

n.s.

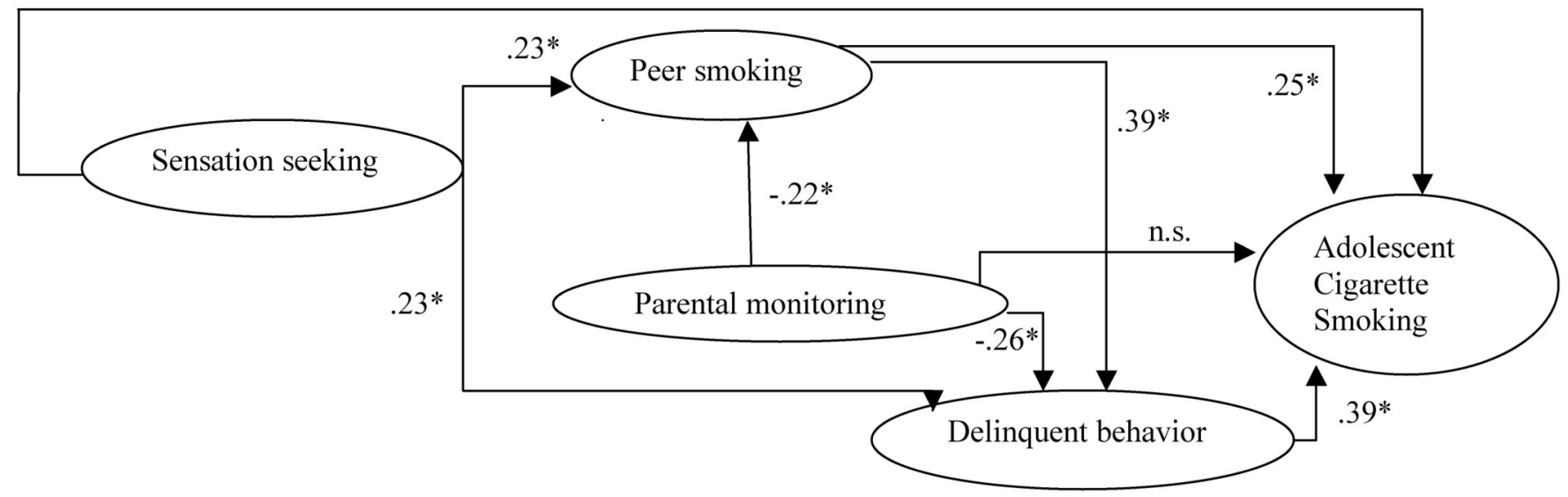

${ }^{*} p<.001$

Fig. (2). Final model for direct and indirect associations between problem behavior theory variables and adolescent cigarette smoking.

school, and grade from variables.

We created our structural model by constructing the paths predicted by our hypotheses (Fig. 1). Results of the SEM indicated that our original model adequately fit the data, $\chi^{2}(1)=2.26, p=.13, C F I=.99, R M S E A=.07$. The final model is presented in Fig. (2). The SEM results are overall consistent with our hypotheses regarding the factors shaping the relationship between personality, perceived environment, and behavior system variables and adolescent cigarette smoking. To summarize, the results of the SEM model demonstrate that: (1) sensation seeking contributes to adolescent cigarette smoking indirectly (but not directly), through the mediation of peer smoking and engagement in delinquent behaviors (H1 not supported, H2 and H3 supported); (2) peer smoking behavior contributes to adolescent cigarette smoking both directly and indirectly, through the mediation of engagement in delinquent behaviors ( $\mathrm{H} 4$ and H5 supported); (3) Parental monitoring contributes to adolescent cigarette smoking indirectly (not directly), through the mediation of peer smoking and engagement in delinquent behaviors (H6 not supported, H7 and H8 supported).

In combination with the zero-order correlation matrix, the results of our SEM demonstrate that the relation between sensation seeking and adolescent smoking is mediated by peer smoking behavior and engagement in delinquent behaviors, positive zero-order correlation between peer smoking and adolescent smoking is mediated by engagement in delinquent behaviors. The relation between parental monitoring and adolescent smoking is mediated by peer smoking and engagement in delinquent behaviors.

\section{DISCUSSION}

The present study examined the relative contributions (both direct and indirect) of personality, perceived environment, and behavior systems in influencing adolescent cigarette smoking. The findings reveal that whereas peer smoking and delinquent behaviors contribute to adolescent smoking directly, sensation seeking and parental monitoring contribute to adolescent smoking indirectly, through the mediation of peer smoking and delinquent behaviors.

\section{Direct Pathways of Influence}

Findings from the present study indicate that only peer smoking behavior and delinquent behaviors predicted adolescent smoking directly. These findings are consistent with prior research where both peer smoking [35, 36] and delinquency [28, 29] were related to cigarette smoking. These findings suggest that adolescents who have more peers who smoke and engage in delinquent behaviors may be rejecting conventional norms, and thus are engaging in cigarette smoking and perhaps other risky behaviors (such as drug use, alcohol consumption, unsafe sex) that were not measured in this study. Given these results, we should examine more closely the dynamics of peer relationships and influences [54].

\section{Indirect/Mediated Pathways of Influence}

First, the present study documented that sensation seeking contributes to having more friends who smoke and engagement in delinquent behaviors, which further predict adolescent cigarette smoking. High sensation seekers tend to have friends who engage in similar risk behaviors. For instance, recent research on marijuana use has documented that high sensation seekers associate more with delinquent friends, have more pro-marijuana discussions with friends, and thereby have a greater tendency for engaging in marijuana consumption behaviors [20]. Therefore, this implies that high sensation seekers choose to socialize more with peers who are engaging in risky behaviors, which may provide them an outlet for engaging in delinquent behaviors, further progressing to adolescent cigarette smoking. We need further longitudinal analyses that examine such "gateway effects" (described as "development sequence of involvement," [19]) that describe the progression from engagement in delinquent behaviors to adolescent cigarette smoking (and possibly to harder drugs).

Second, weak parental monitoring is associated with having more friends who smoke and greater engagement in delinquent behaviors, both further leading to adolescent smoking. This finding is not surprising, given that poor parental monitoring has been associated with adolescent delinquent 
behaviors $[44,45]$ and socialization with peers who engage in substance use [20, 48]. Grusec and Goodnow [55] have explained that weak family relationships and poor monitoring increase the risk of adolescent problem behavior because they fail to provide clear communication of parents' values, undermine motivation for adolescents to attend and comply, and therefore weaken adolescents' internalization of parental values and socialization. Chassin et al. [56] conclude that family-based interventions that aim at increasing parental acceptance, communication, and behavioral control may be a successful way of deterring adolescent smoking. Campaign designers should also target parents - not just adolescents with these messages.

\section{Limitations}

This study is not without limitations. These data were collected from the northeastern United States, and it is not known if these results would generalize to other areas of the country. These data consisted primarily of Hispanic adolescents, and other racial groups (e.g., African Americans, Asians, Caucasians, and Bi/Multi-Racials) were clearly underrepresented. Although these data must be interpreted with sampling biases in mind, obtaining an unbiased sample of adolescents is difficult given limited access, particularly to ask questions about risk behaviors. Also, the study was based on adolescents' self reports. Future studies may include observation of participants' actual behavior or their friends' and families' reports. In the present study, we measured parental monitoring by asking the adolescents to report on the degree to which their parents are aware of their daily plans and know about their interests and activities. Although this method of measuring parental monitoring has been used in prior research [57], it would have been more helpful if we got data from parents as well. We did not have dyadic data, and so relied on adolescents report on parental monitoring.

This study utilized cross-sectional survey data to examine pathways of association, which limits the causal interpretation of results [20]. Future studies could employ longitudinal designs to examine the pathway of influence from peer smoking to engagement in delinquent behaviors to cigarette smoking. This study only identified one personality, two perceived environment, and one behavior systems factors to model adolescent smoking behavior. Future research could look at a different subset of the three system variables, and examine the interplay between systems to explain adolescent cigarette smoking (and other problem behaviors). Finally, we acknowledge the broad scope of the problem behavior theory, and the possibility of including other measures under the three systems, thereby limiting the adequacy of this research.

\section{Implications and Future Research}

The results of this study indicate that the problem behavior theory is a useful and a multidimensional way of examining adolescent smoking behavior. Prior work on examining factors that influence adolescents to smoke in a primarily Hispanic sample has shown that many of the factors examined in this research do contribute to adolescent smoking [58]. However, variables within each system can both directly and indirectly contribute towards adolescent smoking, a line of research that needs attention. This study highlighted that poor parental monitoring can contribute to adolescent smoking. Therefore, interventions could be designed to pro- mote open family communication, strengthening family ties, and inspiring parents and families to connect with their children, similar to The Office of National Drug Control Policy's (ONDCP) [59] media campaign, "Parents: The Anti Drug." Given that the majority of our study sample was Hispanic, it becomes necessary to discuss the social environmental contexts of Hispanic adolescent smoking. Social environmental influences on Hispanic adolescents' substance use behaviors including smoking have been examined in prior research $[60,61]$. These studies stress the significance of examining cultural-specific variables (such as, acculturation). Future research could examine the extent to which the present study variables (both direct and indirect pathways to adolescent smoking) are influenced by cultural factors, particularly in the context of Hispanic adolescent smoking behavior. Additionally, greater understanding of the way adolescents influence each other and are influenced in peer groups may be an avenue for future research because peer smoking has shown to play a significant role in adolescent smoking. The Drug Resistance Strategies Project, conceptualized as a peer pressure model explains adolescent substance use as arising largely out of peer pressure and focuses on teaching adolescents refusal skills for resisting peer pressure [62]. More recently, Greene \& Banerjee [63] classified adolescent responses to cigarette offers utilizing four drug refusal strategies of refuse, explain, avoid, and leave (REAL) and explored how personality factors explain adolescents' use of cigarette refusal strategies. Therefore, future research should focus on extrapolating the complex network of peer smoking and emphasize teaching of refusal skills to adolescents to resist peer pressure to engage in health compromising behaviors such as cigarette smoking.

\section{REFERENCES}

[1] Marshall LM, Schooley M, Ryan H, et al. Youth tobacco surveillance: United States, 2001-2002. CDC Surveillance Summaries 2006; 55: 1-56.

[2] Department of Health and Human Services. Substance Abuse and Mental Health Services Administration. Overview of Findings from the 2002 National Survey on Drug Use and Health (Office of Applied Studies, NHSDA Series H-21, DHHS Publication No. SMA 03-3774). Rockville 2003.

[3] Mowery PD, Farrelly MC, Haviland ML, Gable JM, Wells HE. Progression to established smoking among US youths. Am J Public Health 2004; 94: 331-37.

[4] Fellows JL, Trosclair A, Adams EK, Rivera CC. Annual smoking attributable mortality, years of potential life lost and economic costs: United States 1995-1999. MMWR Morb Mortal Wkly Rep 2002; 51: 300-03.

[5] Warren CW, Jones NR, Eriksen MP, Asma S. Patterns of global tobacco use in young people and implications for future chronic disease burden in adults. Lancet 2006; 367: 749-53.

[6] Centers for Disease Control and prevention (CDC). Annual smoking-attributable mortality, years of potential life lost, and productivity losses - United States, 1997-2001. MMWR Morb Mortal Wkly Rep 2005; 54: 625-28.

[7] US Department of Health and Human Services. Preventing tobacco use among young people: A report of the Surgeon General. Atlanta: U.S. Department of Health and Human Services, Public Health Service, Centers for Disease control and Prevention, National Center for Chronic Disease Prevention and Health Promotion: Office on Smoking and Health 1994.

[8] American Legacy Foundation [homepage on the Internet]. 2000 National Youth Tobacco Survey [updated 2001; retrieved 2007 July 3]. Available from: http://www.americanlegacy.org/168.htm.

[9] American Lung Association [homepage on the Internet]. Adolescent smoking statistics [updated 2003 November; retrieved 2007 June 20]. Available from: http://www.lungusa.org/site/pp.asp?c= dvLUK9O0E\&b=39868. 
[10] Jessor R, Jessor S. Problem behavior and psychosocial development. New York: Academic Press 1977.

[11] Jessor R, Jessor S. In: Mednick SA, Harway M, Finello KM, Eds. Handbook of longitudinal research: Teenage and adult cohorts. Westport: Greenwood Press 1984; vol. 2: pp. 34-61.

[12] Basen-Engquist K, Edmundson EW, Parcel GS. Structure of health risk behavior among high school students. J Consult Clin Psychol 1996; 64: 764-65.

[13] Costa FM, Jessor R, Turbin MS. College student involvement in cigarette smoking: the role of psychosocial and behavioral protection and risk. Nicotine Tob Res 2007; 9(2): 213-24.

[14] Dick DM, Viken R, Purcell S, Kaprio J, Pulkkinen L, Rose RJ. Parental monitoring moderates the importance of genetic and environmental influences on adolescent smoking. J Abnorm Psychol 2007; 116: 213-8.

[15] Greene K, Krcmar M, Walters LH, Rubin DL, Hale JL. Targeting adolescent risk-taking behaviors: the contributions of egocentrism and sensation seeking. J Adolesc 2000; 23: 439-61.

[16] Jessor R. Problem-behavior theory, psychosocial development, and adolescent problem drinking. Addiction 1987; 82: 331-42.

[17] Jessor R, Donovan JE, Costa FM. Beyond adolescence: problem behavior and young adult development. New York: Cambridge University Press 1991.

[18] Turbin MS, Jessor R, Costa FM. Adolescent cigarette smoking: Health-related behavior or normative transgression. Prev Sci 2000; 1: 115-24.

[19] Kandel DB, Jessor R. In: Kandel DB Ed. Stages and pathways of drug involvement: Examining the gateway hypothesis. New York: Cambridge University Press 2002; pp. 365-92.

[20] Yanovitzky I. Sensation seeking and adolescent drug use: The mediating role of association with deviant peers. Health Commun 2005; 17: 67-89.

[21] Zuckerman M. Behavioral expressions and biosocial bases of sensations seeking. New York: Cambridge University Press 1994.

[22] Hoyle RH, Stephenson MT, Palmgreen P, Lorch EP, Donohew L. Reliability and validity of scores on a brief measure of sensation seeking. Pers Individ Dif 2002; 32: 401-14.

[23] Crawford AM, Pentz MA, Chou CP, Li C, Dwyer JH. Parallel developmental trajectories of sensation seeking and regular substance use in adolescents. Psychol Addict Behav 2003; 17: 179-92.

[24] Frankenberger KD. Adolescent egocentrism, risk perceptions, and sensation seeking among smoking and nonsmoking youth. J Adol Res 2004; 19: 576-90.

[25] Skara S, Sussman S, Dent CW. Predicting regular cigarette use among continuation high school students. Am J Health Behav 2001; 25: 147-56.

[26] Segal B, Huba GJ, Singer JL. Drugs, daydreaming, and personality: A study of college youth. Hillsdale: Lawrence Erlbaum Associates 1980.

[27] Donohew R, Hoyle R, Clayton R, Skinner WF, Colon SE, Rice RE. Sensation seeking and drug use by adolescents and their friends: Models for marijuana and alcohol. J Stud Alcohol 1999; 60: 62231.

[28] Bogart LM, Collins RL, Ellickson PL, Klein DJ. Adolescent predictors of generalized health risk in young adulthood: A 10-year longitudinal assessment. J Drug Issues 2006; 36: 571-96.

[29] Mason WA, Hitchings JE, Spoth RL. Emergence of delinquency and depressed mood throughout adolescence as predictors of late adolescent problem substance use. Psychol Addict Behav 2007; 21: 370-81.

[30] Hawkins J, Catalano R, Miller J. Risk and protective factors for alcohol and other drug problems in adolescence and early adulthood: Implications for substance abuse prevention. Psychol Bull 1992; 112: 64-105.

[31] Ennett ST, Bauman KE, Hussong A, et al. The peer context of adolescent substance use: Findings from social network analysis. J Res Adolesc 2006; 28: 159-86.

[32] Reid JL, Manske SR, Leatherdale ST. Factors related to adolescents' estimation of peer smoking prevalence. Health Educ Res 2008; 23: 81-93.

[33] Hoffman BR, Sussman S, Unger JB, Valente TW. Peer influences on adolescent cigarette smoking: A theoretical review of the literature. Subst Use Misuse 2006; 41: 103-55.

[34] Unger JB, Yan L, Shakib S, et al. Peer influences and access to cigarettes as correlates of adolescent smoking: A cross cultural comparison of Wuhan, China, and California. Prev Med 2002; 34 : 476-84.

[35] Engels RCME, Vitaro F, Den Exter Blokland E, de Kemp R, Scholte RHJ. Influence and selection processes in friendships and adolescent smoking behavior: the role of parental smoking. J Adolesc 2004; 27: 531-44.

[36] Madarasová Gecková A, Stewart R, van Dijk JP, Orosová O, Groothoff JW, Post D. Influence of socio-economic status, parents and peers on smoking behaviour of adolescents. Eur Addict Res 2005; 11: 204-9.

[37] Imhonde HO, Aluede O. Smoking intensity among Nigerian secondary schools adolescent smokers. Educ Res Q 2007; 31(2): 55-71.

[38] Pleydon AP, Schner JG. Female adolescent friendship and delinquent behavior. Adolescence 2001; 36: 189-205.

[39] Dillon FR, Pantin H, Robbins MS, Szapocznik J. Exploring the role of parental monitoring of peers on the relationship between family functioning and delinquency in the lives of African American and Hispanic adolescents. Crime Delinq 2008; 54: 65-94.

[40] Barnes GM, Hoffman JH, Welte JW, Farrell MP, Dintcheff BA. Effects of parental monitoring and peer deviance on substance use and delinquency. J Marriage Fam 2006; 68: 1084-104.

[41] Griffin KW, Botvin GJ, Scheier LM, Diaz T, Miller NL. Parenting practices as predictors of substance use, delinquency, and aggression among urban minority youth: moderating effects of family structure and gender. Psychol Addict Behav 2000; 14: 174-84.

[42] Harakeh Z, Scholte RHJ, Vermulst AA, de Vries H, Engels RC. Parental factors and adolescents' smoking behavior: An extension of the theory of planned behavior. Prev Med 2004; 39: 951-61.

[43] Dishion TJ, McMahon RJ. Parental monitoring and the prevention of child and adolescent problem behavior: A conceptual and empirical formulation. Clin Child Fam Psychol Rev 1998; 1: 61-75.

[44] Mounts NS. Adolescents' perceptions of parental management of peer relationships in an ethnically diverse sample. J Adolesc Res 2004; 19: 446-67.

[45] Simons-Morton BG, Chen R, Hand L, Haynie D. Parenting behavior and adolescent conduct problems: reciprocal and mediational effects. J Sch Violence 2008; 7: 3-25.

[46] Bogenschneider K, Wu M-Y, Raffaelli M, Tsay JC. Parental influences on adolescent peer orientation and substance use: The interface of parenting practices and values. Child Dev 1998; 69: 167288 .

[47] Rodgers-Farmer AY. Parental monitoring and peer group association: Their influence on adolescent substance use. J Soc Serv Res 2001; 27(2): 1-18.

[48] Urberg KA, Luo Q, Pilgrim C, Degirmencioglu SM. A two-stage model of peer influence in adolescent substance use: individual and relationship-specific differences in susceptibility to influence. Addict Behav 2003; 28: 1243-56.

[49] Tickle JJ, Hull JG, Sargent JD, et al. A structural equation model of social influences and exposure to media smoking on adolescent smoking. Basic Appl Soc Psych 2006; 28(2): 117-29.

[50] Hornik R, Maklan D, Judkins D, et al. Evaluation of the national youth anti-drug media campaign: second semi-annual report of findings. Rockville: Westat 2001.

[51] National Institute on Drug Abuse. National Household Survey on Drug Abuse. Rockville, MD 2000.

[52] Knobloch LK, Solomon DH, Cruz MG. The role of relationship development and attachment in the experience of romantic jealousy. Pers Relatsh 2001; 8: 205-24.

[53] Bollen KA. Structural equations with latent variables. New York: Wiley 1989.

[54] Kobus K. Peers and adolescent smoking. Addiction 2003; 98: 3755.

[55] Grusec JE, Goodnow JJ. Impact of parental discipline methods on the child's internalization of values: a reconceptualization of current points of view. Dev Psychol 1994; 30: 4-19.

[56] Chassin L, Presson CC, Rose J, Sherman SJ, Davis MJ, Gonzalez JL. Parenting style and smoking-specific parenting practices as predictors of adolescent smoking onset. J Pediatr Psychol 2005; 30: 333-44.

[57] Dick DM, Viken R, Purcell S, Kaprio J, Pulkkinen L, Rose RJ. Parental monitoring moderates the importance of genetic and environmental influences on adolescent smoking. J Abnorm Psychol 2007; 116(1): 213-8.

[58] Smith KH, Stutts MA. Factors that influence adolescents to smoke. J Consumer Affairs 1999; 33(2): 321-57. 
[59] Office of National Drug Control Policy (ONDCP) [homepage on the Internet]. Media Campaign, "Parents: The Anti Drug." [Retrieved 2007 August 1]. Available from: http://www.theantidrug. com/

[60] Horigian VE, Lage O G, Szapocznik J. Cultural differences in adolescent drug abuse. Adolesc Med 2006; 17: 469-498.

[61] Vega WA, Sribney WM, Achara-Abrahams L. Public health matters. Am J Public Health 2003; 93(7): 1057-64.
[62] Hecht ML, Marsiglia FF, Elek-Fisk E, et al. Culturally-grounded substance use prevention: An evaluation of the keeping it R.E.A.L curriculum. Prev Sci 2003; 4: 233-48.

[63] Greene K, Banerjee SC. Adolescents' responses to peer smoking offers: The role of sensation seeking and self-esteem. J Health Commun 2008; 13: 267-86.

(C) Banerjee and Greene; Licensee Bentham Open.

This is an open access article licensed under the terms of the Creative Commons Attribution Non-Commercial License (http://creativecommons.org/licenses/by$\mathrm{nc} / 3.0 /$ /) which permits unrestricted, non-commercial use, distribution and reproduction in any medium, provided the work is properly cited. 